\title{
Mastoparan Dissipates Mitochondrial Transmembrane Potential in the Physiological (ADP-LIKE) Range
}

\author{
Dinara Aliverdieva ${ }^{1,4, *}$, Madina Durzhinskaya $^{2}$, Leona Snezkova ${ }^{3}$ and Dmitry Mamaev ${ }^{4}$ \\ ${ }^{1}$ Caspian Institute of Biological Resources, Russian Academy of Sciences, M. Gadjieva St.,45, Makhachkala, \\ 367000 Russia \\ ${ }^{2}$ Research Institute of Eye Diseases, Rossolimo St., 11A, B, Moscow 119021 Russia \\ ${ }^{3}$ Educational and Scientific Center, M.M. Shemyakin and Yu.A. Ovchinnikov Institute of Bioorganic Chemistry, \\ Russian Academy of Sciences, Miklukho-Maklaya St., 16/10, Moscow 117997, Russia
}

${ }^{4}$ A.N. Bach Institute of Biochemistry, Russian Academy of Sciences, Leninsky pr. 33/2, Moscow, 119071 Russia

\begin{abstract}
Experimental studies of antimicrobial peptides as potential drugs having a pore-forming mechanism of action have attracted increasing interest for clinical applications due to their broad spectrum of activity. Here in a short report, we describe an experimental approach for testing potential drugs using rat liver mitochondria as model and pore-forming peptide mastoparan. We have used tightly coupled mitochondria and a sensitive oximetric cell to study activation of mitochondrial respiration by mastoparan and showed limited dissipation of their transmembrane potential in the presence of this peptide. Mastoparan stabilized this potential synchronously with stabilization of mitochondrial State 4 respiration rate $\left(\mathrm{V}_{4}\right)$. It was concluded that mastoparan dissipates mitochondrial transmembrane potential only in the physiological (adenosine diphosphate (ADP) -like) range. The comparison of side effects of pore-forming peptides on mitochondrial transmembrane potential may be useful for toxicity testing of new drugs.
\end{abstract}

Keywords: Antimicrobial peptides, Mastoparan, Alamethicin, Rat liver mitochondria, Mitochondrial transmembrane potential.

\section{INTRODUCTION}

Mitochondria are the main intracellular power stations in the living cell and transmembrane potential generated by proton pumps (Complexes I, III and IV) is an essential component in the process of energy storage during oxidative phosphorylation [1]. The level of this potential and adenosine triphosphate (ATP) in the cell are kept relatively stable although there are limited fluctuations of both factors reflecting normal physiological activity [1]. However radical and sustained changes of these factors and damage of mitochondrial functions by any medicine inevitably leads to metabolic disorders. In recent years extensive experimental and medical experience in the use of pore-forming peptides as antimicrobial agents has been obtained. However, the lack of simple analytical tools for studying mechanisms of interaction of poreforming peptides with biological membranes remains a problem. The liver is the main organ of detoxification of substances, including drugs that are eliminated from the body. Therefore, liver mitochondria are a good model for studying side effects of drugs and their

\footnotetext{
"Address correspondence to this author at the Caspian Institute of Biological Resources, Russian Academy of Sciences, M. Gadjieva St., 45, Makhachkala, 367000 Russia; Tel: +78722675905;

E-mail: dinara_inbi@mail.ru
}

hepatotoxicity. Mastoparan and its analogs displayed a broad-spectrum antimicrobial activity against bacteria and fungi and were highly potent against antibioticresistant bacteria [2]. The mastoparans are 14 amino acids in length with the $\mathrm{C}$-terminus amidated and rich in hydrophobic and basic amino acids, which leads to amphipathic chemical character, adopting a-helical secondary structure under proper conditions [3]. Due to biological activities, showing histamine releasing from mast cells, antimicrobial and hemolytic activities, mastoparans have been developed for pharmacological research and for therapeutic use, in particular, as antimicrobial agents [4-6]. The mastoparan peptide is known as an inducer of the mitochondrial permeability transition. Although mastoparan was suggested to interact with a proteinaceous target in mitochondria to induce this transition, the mechanism of mastoparan action have not yet been investigated [7].

\section{MATERIAL AND METHODS}

In the course of the experiment the following reagents were used: rhodamine 123, adenosinediphosphate disodium salt (ADP), 4-(2-hydroxyethyl)-1piperazineethane sulfonic acid (Hepes) (Sigma), carbonylcyanide(4-trifluoromethoxy)phenylhydrazone 
(FCCP) (Aldrich), $\quad$ - 3,5-di-tert-butyl-4oxybenzylidenemalononitrile (SF) (Sumitomo Chem. Co.), Trichoderma viride alamethicin (Fluka), sucrose (Merck), $\mathrm{KCl}, \quad \mathrm{KH}_{2} \mathrm{PO}_{4}, \quad \mathrm{MgCl}_{2}$, ethylenediaminetetraacetic acid (EDTA), succinic acid of special pure grade (Reakhim), tris(hydroxymethyl)aminomethane (Tris), rotenone, horse cytochrome c, Serva Blue G (Serva). Mastoparan from Vespa orientalis (INLKAIAALVKKVL $\left(\mathrm{NH}_{2}\right)$ ) was isolated as shown in [12].

For isolation of tightly coupled intact rat liver mitochondria the modified Weinbach method was used (centrifugation: $5500 \mathrm{~g}$ for 10 minutes), while all fractions of these organelles are sedimented at $12000 \mathrm{~g}$ [8]. Modification of Bradford method was used for determination of mitochondrial protein [9]. Rates of succinate oxidation of rat liver mitochondria $(v)$ and the mitochondria respiratory control $(R C)$ ratio were determined in thermostatic cell at $25^{\circ} \mathrm{C}$ with quick response oxymetric electrode [10]. In the presence of succinate in all used incubation media the Chance RC was about $5.0-5.2$. Mitochondrial incubation medium (pH 7.2) contained $4 \mu \mathrm{M}$ horse cytochrome $\mathrm{c}, 30 \mathrm{mM}$ Tris, $1.5 \mu \mathrm{M}$ rotenone, $125 \mathrm{mM}$ sucrose, 2 mMEDTA, $10 \mathrm{mM} \mathrm{KH} \mathrm{KO}_{4}, 10 \mathrm{mM}$ sodium succinate, $6 \mathrm{mM}$ $\mathrm{MgCl}_{2}$,. Transmembrane mitochondrial potential was determined in the same media as control oximetric measurements, using Shimadzu RF-5301 PC fluorometeras described in [11]. We showed that rhodamine 123 had no influence on the respiration ratesin the absence and in the presence of mastoparan. The principle of this method is that under the influence of the potential the amphiphilic charged rhodamine 123 enters the membrane and in its hydrophobic environment the dye changes its fluorescence spectrum [11]. The authors gave calibration dependence between the value of artificially created transmembrane potassium potential of rat liver mitochondrial membrane and the value of altered fluorescence. We used this linear relationship in the work because we isolated rat liver mitochondria using the same technique as the authors of the paper [11] and used the same incubation medium. The empirical equation $\Delta \mathrm{F} / \mathrm{F}=(\Delta \Psi-60) / 323$ [11] was used for calculation of the value of potential $(\Delta \Psi)$, where $\Delta F$ was the difference between fluorescence values obtained before and after addition of protonophore SF, $F$ was fluorescence in the presence of SF. Oximetric effects of mastoparan and alamethicin were normalized by the initial rate of mitochondrial respiration $\left(v_{0}\right)$.
Monocationic media in which all cations except magnesium were replaced by $\mathrm{K}^{+}$(potassium medium) or $\mathrm{Li}^{+}$(lithium medium) and $10 \mathrm{mM}$ Hepes instead of Tris were used. The scheme of oximetric experiment: we successively added pore forming peptide (mastoparan or alamethicin) in several concentrations and a protonophore (FCCP) to an oximetric cell containing the mitochondrial incubation medium and suspension of mitochondria. The addition of FCCP showed that the transmembrane potential of mitochondria was partially preserved, since this protonophore caused significant activation of respiration. The scheme of fluorometric experiment: to a cell containing the mitochondrial incubation medium and $0.4 \mu$ Mrhodamine 123 we successively added a suspension of mitochondria and pore forming peptide in several concentrations, measuring the changes in fluorescence.

\section{RESULTS AND DISCUSSION}

Earlier, it was shown that the transmembrane cationic current induced in rat liver mitochondria by various inducers of membrane permeability linearly depends on the activation of the mitochondrial respiration [13]. Figure 1A shows activation of mitochondrial respiration by addition of mastoparan in monocationic potassium and lithium incubation media, Figure 1B shows changes in relative rhodamine 123 caused fluorescence, proportional to mitochondrial transmembrane potential. In both incubation media mastoparan stabilized transmembrane potential synchronously with stabilization of mitochondrial v4 activation. In many repetitions we observed that this potential stabilized and reached a plateau in the presence of mastoparan in 2-5 (up to 10) minutes. Unlike this another peptide alamethicin continuously decreased transmembrane potential for critical values (see Figure 1B, the insert) synchronous tomitochondrial v4 activation (not shown). Mastoparan and alamethicin (in the highest concentrations used) activated mitochondrial $\mathrm{v} 4$ to a level stable for $20 \mathrm{~min}$ and mitochondria appeared to be stable during this interval of time. A close results for physiologically different cations such as potassium and lithium (toxicity of lithium on isolated mitochondria was shown in [14]), indicated that the effect of the pore-forming peptides on mitochondria was associated precisely with induced permeability of mitochondrial inner membrane. In the control measurements the value of activation of mitochondrial $v 4$ in the presence of protonophore SF in potassium medium was equal to the same value in lithium medium (data not shown). 
A

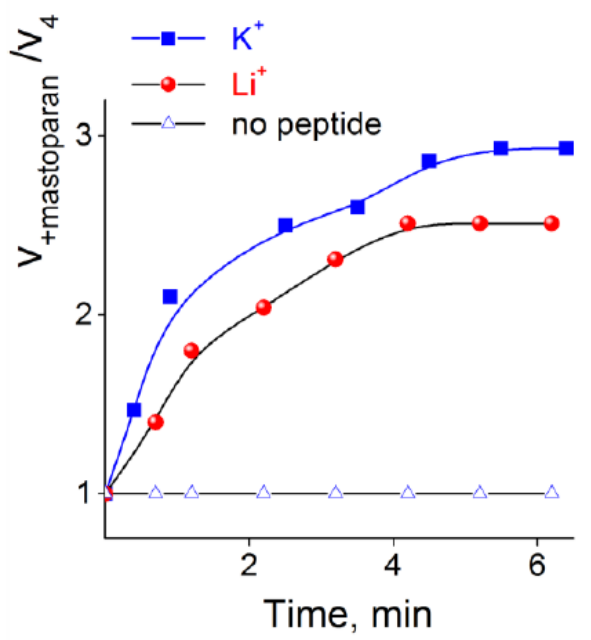

B

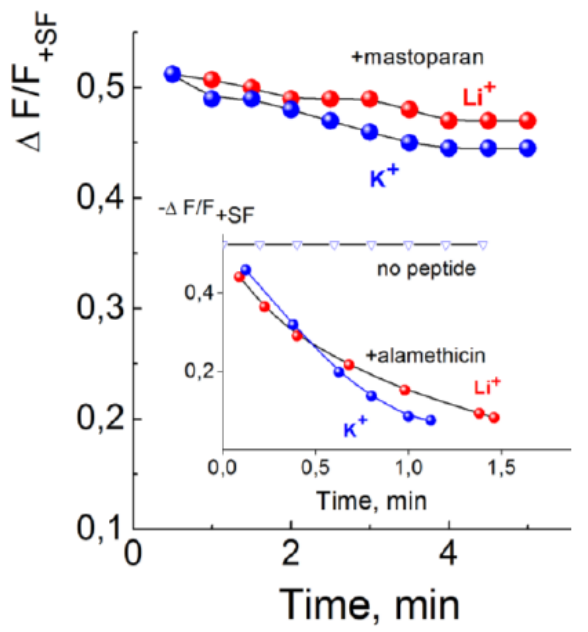

Figure 1: A. Time-course of activation of mitochondrial v4 respiration by $500 \mathrm{nM}$ mastoparan in potassium medium $\left(\mathrm{K}^{+}\right)$and lithium medium $\left(\mathrm{Li}^{+}\right)(\mathrm{A})$, and time course of relative rhodamine 123 fluorescence changes (proportional to mitochondrial trans membrane potential), the inset demonstrates data in the presence of $100 \mathrm{nM}$ alamethicin in potassium medium ( $\mathrm{K}^{+}$) and lithium medium $\left(\mathrm{Li}^{+}\right)(\mathbf{B})$. The concentration of mitochondria was $0.25 \mathrm{mg} / \mathrm{ml}$. F - fluorescence in the presence of SF. Plots were representative for three independent preparations of mitochondria.

As was shown earlier the value ( $v+$ peptide/v4) was proportional to cationic current induced by pore-forming peptides at stabilized potential using mitochondrial preparations [13]. In comparison: complex procedures were required for maintenance of constant liposomal transmembrane potential [15]. In contrast to liposomal the corresponding potential generated by mitochondrial respiratory chain existed for several minutes. Under these conditions, the peptide self-association order was measured only for peptides in transmembrane conformation. The effect of pore-forming peptides was accompanied by decrease of mitochondrial transmembrane potential. However, the magnitude of activation of mitochondrial $\mathrm{v} 4$ by different peptides did not correlate with this effect on transmembrane potential.

Mitochondria play an important role in cell homeostasis. Mitochondrial transmembrane potential is a driving force for transport of ions and proteins which are necessary for mitochondrial functioning. It is difficult to determine the "optimal" values of transmembrane potential for the cells and mitochondria, however a long-lasting drop or rise of its normal levels may induce unwanted loss of cell viability and be a cause of various pathologies [1]. Physiological activator of respiration ADP also dissipates mitochondrial transmembrane potential in the normal conditions of the living cell. A degree of this dissipation as compared with protonophore FCCP varies from 0.2 to $0.25 \%$ accordingly to the method of transmembrane potential determination [16, 11]. However such dissipation is not critical for the steady internal physical and chemical conditions maintaining by the living cell.

\section{CONCLUSION}

It was earlier shown that in the presence of melittin mitochondria retained stable transmembrane potential in contrary to alamethicin and 1,7,21,23tetraacetylmelittin [13]. Here we have shown that in the presence of mastoparan transmembrane potential stabilized and reached a long plateau in a few minutes. Mastoparan dissipated mitochondrial potential only in the physiological (ADP-like) range and for this reason this peptide may be less harmful in therapeutic use than peptides radically dissipating potential. Poreforming peptides are promising drugs. In the course of comparative testing of pore-forming peptides on their potential toxicity, the active membrane concentration of the peptide, activating mitochondrial v 4 by $200 \%$ and concentration of peptide causing lysis of mitochondria must also be taken into account.

\section{REFERENCES}

[1] Zorova LD, Popkov VA, Plotnikov EY, Silacheva DN, Pevznera IB, Jankauskasa SS, et al. Mitochondrial membrane potential. Anal Biochem 2018; 552: 50-59. https://doi.org/10.1016/j.ab.2017.07.009

[2] Irazazabal LN, Porto WF, Ribeiro SM, Casale S, Humblot V, Ladram A, Franco OL. Selective amino acid substitution reduces cytotoxicity of the antimicrobial peptide mastoparan. Biochim Biophys Acta 2016; 1858(11): 2699-2708. https://doi.org/10.1016/j.bbamem.2016.07.001 
[3] Konno K, Kazuma K, Rangel M, Stolarz-de-Oliveira J, Fontana $\mathrm{R}$, Kawano M, Fuchino $\mathrm{H}$, et al. New Mastoparan Peptides in the Venom of the Solitary Eumenine Wasp Eumenesmicado. Toxins (Basel) 2019; 11(3): pii: E155. https://doi.org/10.3390/toxins11030155

[4] Moreno M, Giralt E. Three valuable peptides from bee and wasp venoms for therapeutic and biotechnological use: melittin, apamin and mastoparan. Toxins (Basel) 2015; 7(4): 1126-1150. https://doi.org/10.3390/toxins7041126

[5] Chen X, Zhang L, Wu Y, Wang L, Ma C, Xi X, BinindaEmonds ORP, et al. Evaluation of the bioactivity of a mastoparan peptide from wasp venom and of its analogues designed through targeted engineering. Int J Biol Sci 2018; 14(6): 599-607. https://doi.org/10.7150/ijbs.23419

[6] Howl J, Howl L, Jones S. The cationic tetradecapeptide mastoparan as a privileged structure for drug discovery: Enhanced antimicrobial properties of mitoparan analogues modified at position-14. Peptides 2018; 101: 95-105. https://doi.org/10.1016/j.peptides.2018.01.007

[7] Yamamoto T, Ito M, Kageyama K, Kuwahara K, Yamashita $\mathrm{K}$, Takiguchi $\mathrm{Y}$, Kitamura $\mathrm{S}$, et al. Mastoparan peptide causes mitochondrial permeability transition not by interacting with specific membrane proteins but by interacting with the phospholipid phase. FEBS J 2014; 281(17): 393344.

https://doi.org/10.1111/febs.12930

[8] Mosolova IA, Gorskaya IA, Sholtz KF, Kotelnikova AV. Preparation from rat liver of tightly coupled mitochondria with storage stability. Vopr Med Khim1971; 17: 286-90.

[9] Aliverdieva DA, Sholtz KF. Quantitative determination of total mitochondrial protein with Coomassie. Prikl Biokhim Mikrobiol 1984; 20(6): 823-830.

[10] Aliverdieva DA, Mamaev DV, Lagutina LS. Parameters of the succinate transport into Saccharomyces cerevisiae cells after prolonged cold preincubation. Prikl Biochim Microbiol 2009; 45(5): 577-85.

https://doi.org/10.1134/S0003683809050111

[11] Emaus RK, Grunwald R, Lemasters JJ. Rhodamine 123 as a probe of transmembrane potential in isolated rat-liver mitochondria: spectral and metabolic properties. Biochim. Biophys. Acta 1986; 850: 436-448. https://doi.org/10.1016/0005-2728(86)90112-X

[12] Miroshnikov Al, Snezkova LG, Nazimov IV, Reshetova OI, Rozykov BV, Gushin IS. Structure and properties of histamine-releasing peptides from Vespa orientalis venom. Bioorg Chem 1981; 7: 1467-1478.

[13] Aliverdieva D, Mamaev D, Snezhkova L, Sholtz C. Evaluation of molecularity of rate-limiting step of pore formation by antimicrobial peptides studied using mitochondria as a biosensor. Toxicology in vitro 2012; 26 : 939-949. https://doi.org/10.1016/j.tiv.2012.04.006

[14] Salimi A, Gholamifar E, Naserzadeh P, Hosseini MJ, Pourahmad J. Toxicity of lithium on isolated heart mitochondria and cardiomyocyte: A justification for its cardiotoxic adverse effect. J Biochem Mol Toxicol 2017; 31(2).

https://doi.org/10.1002/jbt.21836

[15] Polozov IV, Polozova Al, Tytler EM, Anantharamaiah GM, Segrest JP, Woolley GA, Epand RM. Role of lipids in the permeabilization ofmembranes by class $L$ amphipathic helical peptides. Biochemistry 1997; 36: 9237-9245. https://doi.org/10.1021/bi970045

[16] Chowdhury SR, Djordjevic J, Albensi BC, Fernyhough P. Simultaneous evaluation of substrate-dependent oxygen consumption rates and mitochondrial membrane potential by TMRM and safranin in mito chondria. Biosci Rep 2015; 36(1): e00286.

https://doi.org/10.1042/BSR20150244

http://dx.doi.org/10.15379/2410-1869.2019.06.02.01

(c) 2019 Aliverdieva et al.; Licensee Cosmos Scholars Publishing House.

This is an open access article licensed under the terms of the Creative Commons Attribution Non-Commercial License (http://creativecommons.org/licenses/by-nc/3.0/), which permits unrestricted, non-commercial use, distribution and reproduction in any medium, provided the work is properly cited. 